\title{
A new methodology for identification of potential pay zones from well logs: Intelligent system establishment and application in the Eastern Junggar Basin, China
}

\author{
Guo Dali, ${ }^{1,2}$ Zhu Kai ${ }^{1,2 *}$, Wang Liang1,3, Li Jiaqi ${ }^{4}$ and Xu Jiangwen ${ }^{4}$ \\ ${ }^{1}$ State Key Laboratory of Oil and Gas Reservoir Geology and Exploitation, Southwest Petroleum University, Sichuan \\ 610500, China \\ ${ }^{2}$ School of Sciences, Southwest Petroleum University, Sichuan 610500, China \\ ${ }^{3}$ School of Geosciences and Technology, Southwest Petroleum University, Sichuan 610500, China \\ ${ }^{4}$ Engineering Technology Research Institute, Xinjiang Oilfield Branch of CNPC, Xinjiang 834000, China \\ (C) China University of Petroleum (Beijing) and Springer-Verlag Berlin Heidelberg 2014
}

\begin{abstract}
In recent years, as the exploration practices extend into more complicated formations, conventional well log interpretation has often shown its inaccuracy and limitations in identifying hydrocarbons. The Permian Wutonggou Formation hosts typical clastic reservoirs in the Eastern Junggar Basin. The sophisticated lithology characteristics cause complex pore structures and fluid properties. These all finally cause low well testing agreement rate using conventional methods. Eleven years' recent statistics show that 12 out of 15 water layers have been incorrectly identified as being oil or oil/water layers by conventional well log interpretation. This paper proposes a methodology called intelligent prediction and identification system (IPIS). Firstly, parameters reflecting lithological, petrophysical and electrical responses which are greatly related to reservoir fluids have been selected carefully. They are shale content $\left(V_{\text {sh }}\right)$, numbered rock type $(\mathrm{RN})$, porosity $(\Phi)$, permeability $(K)$, true resistivity $(\mathrm{RT})$ and spontaneous-potential (SP). Secondly, $V_{\mathrm{sh}}, \Phi$ and $K$ are predicted from well logs through artificial neural networks (ANNs). Finally, all the six parameters are input into a neuro-fuzzy inference machine (NFIM) to get fluids identification results. Eighteen new layers of $145.3 \mathrm{~m}$ effective thickness were examined by IPIS. There is full agreement with well testing results. This shows the system's accuracy and effectiveness.
\end{abstract}

Key words: Eastern Junggar Basin, potential pay zone identification, well log interpretation, intelligent system, neural network, neuro-fuzzy inference machine

\section{Introduction}

In recent years, as the exploration practices expand into much wider areas, formation situations have become more and more complicated than before. It is a big challenge for conventional well log interpretation techniques to identify potential pay zones accurately. The Permian Wutonggou Formation in the eastern Junggar Basin hosts some of the most important clastic reservoirs in the Xinjiang oil field. The reservoirs are in various types of lithology with sophisticated characteristics: siltstone, fine sandstone, conglomerate, while some are filled with ash and tuff, some are filled with clay and shale to different degrees. They cause various and complex pore structures and have a high bound water saturation averaging $47 \%$. Statistics for 2001-2011 show that 12 of 15

*Corresponding author. email: zhu_kaicom@163.com

Received February 5, 2013 water layers have been incorrectly identified as oil or oil/ water layers by conventional well log interpretation. It has increased well testing costs too much.

Commonly, pay zones can be recognized by drawing cross plots (Cheng, 2008). This is effective under specific formation situations. The RT- $\Phi$ cross plot should be used under several situations: single rock type, rarely shale content and stable formation water properties. However, this method often considers too few factors to recognize more complex layer situations. Frequently, because of the complex formations, it is very difficult to get effective cross plots. The Permian Wutonggou Formation is an example of this problem. Also, it is time consuming and hard to handle when too much data with inaccuracy, fuzziness and redundancy is considered. So it is necessary to resort to other methods to resolve these specific problems. In fact, some researchers have tried intelligent methods to extract fluid information from well logs for better accuracy. Zhou et al (1993) tried to 
identify hydrocarbons from well logs by using a fuzzy neural network (FNN). Elshafei and Hamada (2007) have also used artificial neural networks (ANN) to identify potential layers in shaly sand reservoirs. Gao et al (2009) used an emergent spontaneous organizing feature map to get better accuracy. Kadkhodaie et al (2009a; 2009b) and Jafari et al (2011) designed a CMNN (committee machine neural network) to predict NOC and TOC from log data to find hydrocarbon potentials. Khoshnoodkia et al (2011) also predicted the TOC by using fuzzy theory. Karimpouli et al (2010) used a new supervised CMNN to improve ANN's performance. Li et al (2011) used a decision tree (DC), support vector machine (SVM) and rough set (RS) to identify low gas-saturation reservoirs. Fernandes (2012) also used ANNs to determine the presence of hydrocarbons with well logs and formula equations. Cranganu and Breaban (2013) have used support vector regression (SVR) to estimate sonic log distributions from conventional well logs. In recent years, there have been many other studies on predicting petrophysics (Zhang et al, 2006; Ye et al, 2011; Jafari and Moghadam, 2012; Wang et al, 2010), lithology (Wang and Zhang, 2008), classification (Zhu et al, 2010; Yu et al, 2011) and identification (Zhang et al, 2011) from well logs or other parameters. Many other intelligent methods have been used (Wu et al, 2009; Tan et al, 2010; Jafari and Mashohor, 2013).

There are many factors affecting underground fluid identification. Lithological, petrophysical properties and electrical responses comprehensively reflect fluid information. Meanwhile, these properties are implicated deeply in large numbers of well logs. Prediction models should be elaborately founded on careful selection and analysis of massive, fuzzy, redundant data considering real formation situations. This is always challenging work. However, the literature above have only records simple methods to predict fluid information directly from well logs. Complex problems have been over simplified. Based on these, this paper has proposed a methodology called intelligent prediction and identification system (IPIS), which considered specific situations in the Eastern Junggar Basin. The IPIS based on ANN and FIS theory divides the problem into two parts and resolves it by steps. There are mainly three parts as follows. The ideas of IPIS are in the first part. Data pre-processing and construction of models are in the second. An example and applications have been shown finally.

\section{The methodology of intelligent systems}

\subsection{Reservoir characteristics}

Basically lithological, petrophysical properties and underground electrical responses provide fluid information. It is essential to estimate reservoir characteristics to check the sensitive log parameters and then to design the IPIS objectively. Some basic information is shown in Table 1. The details are as follows.

1) The reservoirs are found in various lithology types: siltstone, fine sandstone, sandy conglomerate and so on. Some are filled with ash and tuff, while most are filled with clay and shale to different degrees. They are divided into four classes by grain size in Table 1 . The finer the formation, the more bound water will be present. $47 \%$ montmorillonite is contained in clay and shale in average. It will expand when encountering water and block micropores.

2) The average porosity is $12 \%$, while the average permeability is $4.4 \mathrm{mD}$. Complex pore structure determines low movable fluid porosity and permeability.

3) Complex lithological properties and pore structures result in intricate fluid distribution. The average bound water saturation from core data is $47 \%$. For the well log of true resistivity (RT), an oil layer is $4.36-32.7 \Omega \cdot \mathrm{m}$ with an average $12.8 \Omega \cdot \mathrm{m}$, while RT of a water layer is $3.37-16.9 \Omega \cdot \mathrm{m}$ with $8.07 \Omega \cdot \mathrm{m}$ as the average value. As these parameters overlap they cannot distinguish oil from water.

In a word, the variance of lithology and mineral components causes heterogeneity of pore structure. And both of them are the major causes to determine poor electrical response. They comprehensively reflect intricate fluid distributions.

\subsection{Model idea and method}

Definitely, fluid information affects a large number of $\log$ data. It is often difficult and inaccurate to extract valuable fluid data from them directly. In fact, this problem can be processed by steps. The proposed methodology, the intelligent prediction and identification system (IPIS), mainly consists of two steps. 1) Based on understanding formation situations, select and predict parameters reflecting lithological, petrophysical and electrical responses which are

Table 1 Formation characteristics

\begin{tabular}{|c|c|c|c|c|c|c|c|c|c|c|}
\hline \multirow{2}{*}{ Lithology } & \multicolumn{2}{|c|}{ Shale, $\%$} & \multicolumn{2}{|c|}{ Throat radius, $\mu \mathrm{m}$} & \multicolumn{2}{|c|}{ Porosity, \% } & \multicolumn{2}{|c|}{ Permeability, $\mathrm{mD}$} & \multicolumn{2}{|c|}{ Bound water saturation, $\%$} \\
\hline & Range & Mean & Range & Mean & Range & Mean & Range & Mean & Range & Mean \\
\hline Mudstone with sand & $9.5-13.1$ & 10.8 & $0.08-1.87$ & 1.02 & 2.1-14.9 & 7.6 & $0.01-12.5$ & 2.45 & $44.8-58.9$ & 54.7 \\
\hline Silt and fine sandstone & $7.8-9.6$ & 8.2 & $0.69-1.88$ & 1.51 & $1.2-21.1$ & 11.1 & $0.42-15.9$ & 4.56 & $45.6-54.2$ & 49.1 \\
\hline Medium and coarse sandstone & $6.9-8.2$ & 7.4 & $1.01-2.3$ & 1.32 & $5.2-24.9$ & 12.5 & $1.38-45.1$ & 4.87 & $38.9-49.6$ & 44.8 \\
\hline Conglomerate & $3.6-7.2$ & 5.6 & $1.3-2.2$ & 1.54 & $6.6-24.1$ & 16.7 & $5.04-28.9$ & 5.65 & $29.7-44.8$ & 38.7 \\
\hline
\end{tabular}


closely related to formation fluid recognition. 2) Put these parameters into an inference system to identify fluids directly. Step 1 concentrates and abstracts key information from large fuzzy and redundant data, and then provides critical inputs for step 2 to get best results.

The selection of inputs from step 1 to step 2 is of great importance. When two potential layers have similar pore structures and electrical responses, the finer lithology layer with higher shale content is likely to be a pay one (Cheng, 2008). If two layers have similar lithological properties and electrical responses, the more complex pore structure layer may have oil potential. Certainly, two layers with almost the same lithology and petrophysical properties will be normally distinguished by subtle differences of electrical parameters. Considering the specific formation in this paper, shale content $\left(V_{\text {sh }}\right)$ and rock type (RN) are chosen here to describe lithology. $\Phi$ and $K$ are considered together to describe pore structure situation. True resistivity (RT) and spontaneous-potential (SP) will be chosen to reflect fluid properties. Normally, shale content may be mainly defined from gamma ray counts (GR) by empirical formulae $(\mathrm{Li}, 2006)$ or other well logs. The sand rock type is often determined by sandstone grain size. $\Phi$ and $K$ are highly related to well $\operatorname{logs}$ (Amaefule et al, 1993; Bloch, 1991). ANNs are designed instead of conventional methods to better determine formation parameters here. Three ANN models are used to train and calculate $V_{\text {sh }}, \Phi$ and $K$ respectively. Rock types are labeled by numbers. RT and SP are obtained from log data.

Thus, three types of property parameters which contain shale content, rock type number, porosity, permeability, true resistivity and spontaneous-potential are obtained as the inputs for the next step-the neuro-fuzzy inference machine (NFIM). It is also the essence of IPIS. The fuzzy inference system (FIS) (Li, 1998) is based on fuzzy set and expert system theories. When it is too hard or expensive to express the relationship between inputs and outputs by exact mathematical models, the FIS will be used. All input data should be fuzzified into fuzzy sets and output data would be defuzzified from fuzzy sets when an FIS works. Fuzzy relationships between inputs and outputs are expressed as IF-THEN rules based on expert knowledge. However, fuzzy rules are often hard to get from a large amount of data. The neuro-fuzzy inference machine technique that combines ANN and FIS has the advantages of both fuzzy inference and neural network. It can learn fuzzy rules from large amounts of data by training and checking. Fig. 1 shows the architecture of IPIS. The details can be found in the following part.

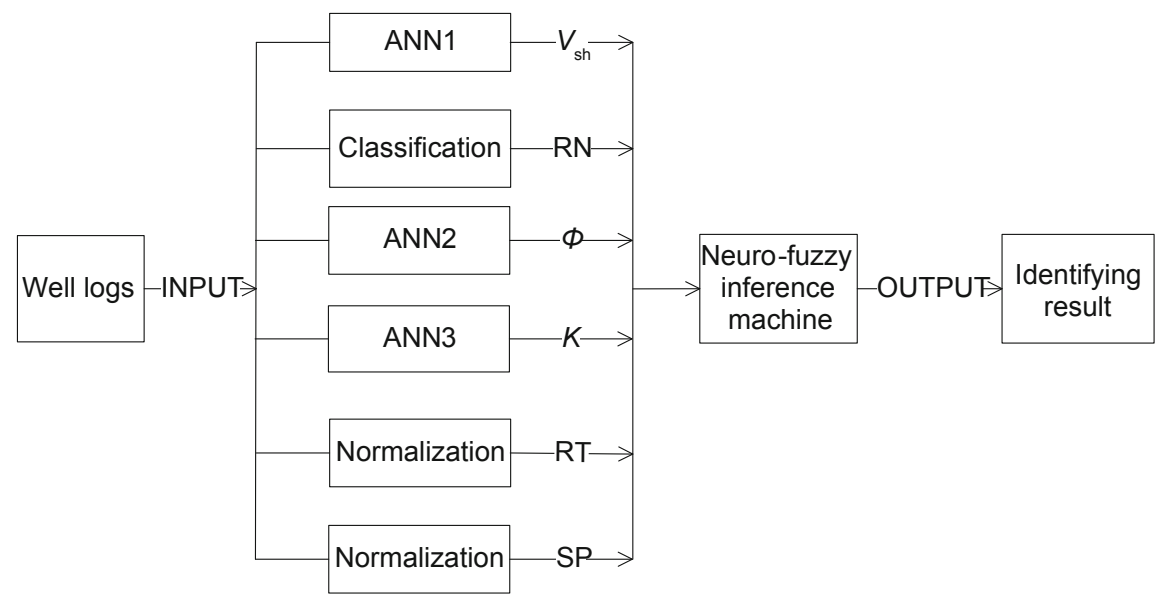

Fig. 1 Architecture of IPIS

\section{Establishment of IPIS}

\subsection{Data selection and preparation}

All the layers of exploration wells in recent eleven years are considered. These data contain well logs AC (acoustic time), CNL (compensated neuron log), DEN (density log), RT (true resistivity), RI (invaded zone resistivity), RXO (flushed zone resistivity), GR (gamma ray), and SP (spontaneous potential), core data (shale content, porosity, permeability) and well testing results. The data are suffering data deficiency and redundancy to some degree. It is necessary to pick out the key data of key wells carefully. The rules are as follows: 1) layers with complete data should be chosen first; 2) layers from different blocks with different well testing conclusions should be considered equally; 3 ) all the layers with core data should be involved to provide enough training data for prediction models. Under these rules, 48 layers of 26 wells with well logs and well testing results and 315 core data points were selected.

\subsection{Construction of ANNs}

The backward propagation (BP) network is a supervised training technique that sends the input values forward through the network then computes the difference between calculated output and corresponding desired output from the training data. The error is then propagated backward through the net, and the weights are adjusted during a number of iterations named epochs. The course stops when the calculated values best approximate the desired outputs (Bhatt and Helle, 2002). Three-layer BP networks with one hidden layer are used here. The Levenberg-Marquardt (LM) algorithm is used in this paper for its fast convergence speed (Burney et al, 2004). The tan-sigmoid and linear equations were taken as activation functions for hidden and output layers respectively (Hagan et al, 1996). Two data groups are considered (90\% points for training and $10 \%$ for checking). All inputs are normalized by 
Eq. (1) before training.

$$
\bar{x}=\frac{x-x_{\min }}{x_{\max }-x_{\min }}
$$

The most important decisions for ANNs are to choose input log variables and determine net architectures. It is often hard to determine the neuron number of hidden layers since there is no common calculation formula. In this paper, input variables and the hidden layer neuron number are determined by lots of numerical experiments with Matlab software. Table 2 shows the performance (mean square error, MSE) under different $\log$ variables with different hidden layer neuron numbers. In order to get the best net structures, almost all possible input variable sets were considered in numerical experiments: 4, 5, 6, 7, 8 variables from all eight well logs were tested in turn. And each input component considered five kinds of hidden layer neuron numbers: $8,9,10,11$, 12. Thus, totally 815 times of numerical experiments were conducted for each output item: $V_{\mathrm{sh}}, \Phi$ and $K$. In light of space restrictions only the top performance sets are shown here. The best models were chosen for IPIS. Figs. 2-4 show their performances.

Different rock types have different reservoir abilities. Since rock types are related to well testing results, their numbers must be ordered. The ordered rules are: if one rock type has more oil production, it should be labeled with a larger number. Else if two rock types have almost the same oil production, the rock type with better petrophysical properties should be labeled larger. Here, numbers 1 to 4 represent in turn mudstone with sand, silt and fine stone, medium and coarse gritty, and conglomerate.

Table 2 Performance of ANNs with best input group and structure

\begin{tabular}{ccccc}
\hline Items & Input variables & Hidden layer neurons & Training MSE & Checking MSE \\
\hline$V_{\text {sh }}$ & AC, DEN, GR, SP, RT & 8 & 0.175 & 0.231 \\
$\Phi$ & AC, CNL, DEN, GR, RT, RT/RXO & 10 & 0.089 & 0.128 \\
$K$ & AC, CNL, DEN, GR, RT/RXO & 11 & 0.105 & 0.139 \\
\hline
\end{tabular}

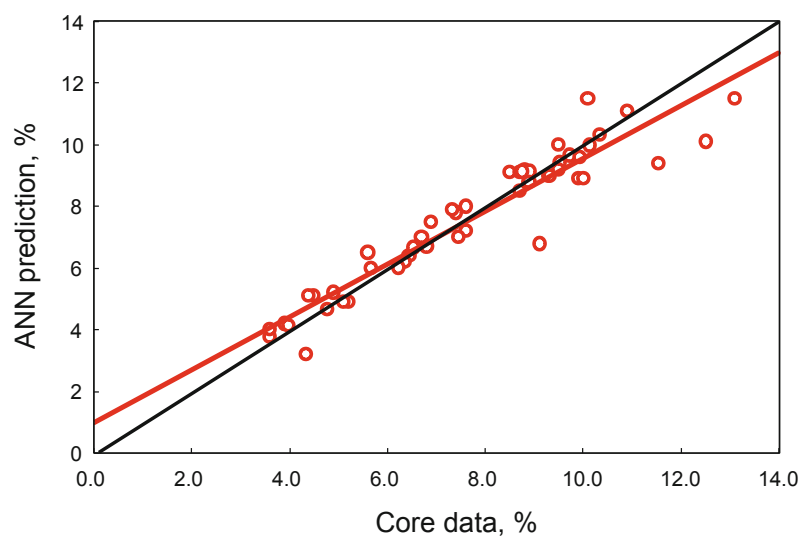

Fig. 2 ANN1 performance to predict shale content

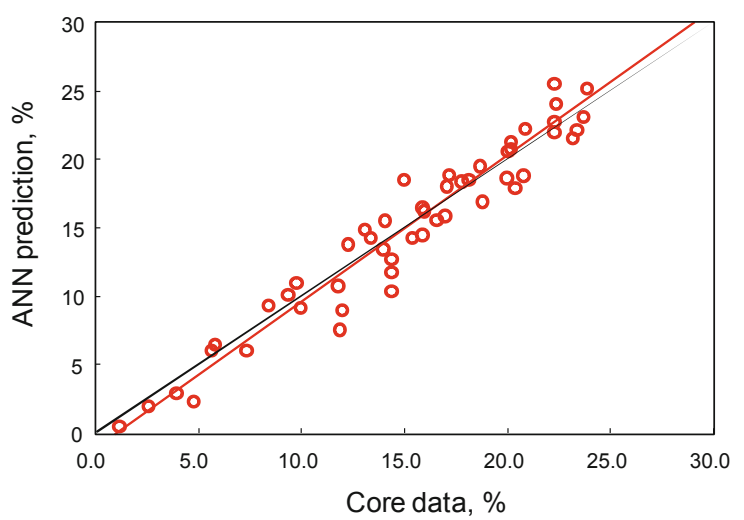

Fig. 3 ANN2 performance to predict porosity

\subsection{Construction of the NFIM}

Fig. 5 shows a neuro-fuzzy inference machine with $n$ inputs and 1 output based on T-S (Takagi-Sugeno) fuzzy model ( $\mathrm{Li}, 2010)$. The net contains five layers totally. For

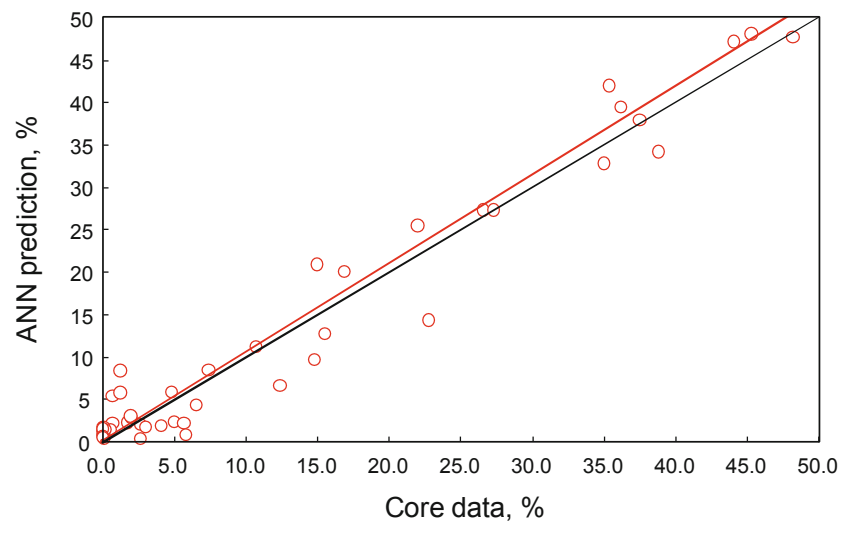

Fig. 4 ANN3 performance to predict permeability

the second layer, $\mu_{i}^{j}$ represents the membership degree of the $i$ th input to the $j$ th fuzzy set. A Gaussian function given by Eq. (2) can be used as the membership function (MF). $c_{i j}$ and $\sigma_{i j}$ represent the center and width of the function. The fitness value for each rule is calculated by Eq. (3) in the third layer, where $m=m_{1} m_{2} \ldots m_{n}$. The fourth layer is normalization: $\bar{\alpha}_{j}=\alpha_{j} /\left(\alpha_{1}+\alpha_{2}+\ldots+\alpha_{m}\right)$. Eq. (4) shows the weights calculation formula. The output data in the fifth layer can be given as Eq. (5). The NFIM should be trained by error back-propagation algorithm as the BP network to get the best MFs and weights with minimum errors (Li, 2010; Jafari and Mashohor, 2013). In this paper, 6 inputs and 1 output have been considered in NFIM. Fig. 6 shows the workflow of NFIM.

$$
\begin{aligned}
& \mu_{i}^{j}=\mathrm{e}^{\frac{\left(x_{i}-c_{i j}\right)^{2}}{\sigma_{i j}}} \\
& \alpha_{j}=\mu_{1}^{i_{1}} \mu_{2}^{i_{2}} \ldots \mu_{n}^{i_{n}}
\end{aligned}
$$




$$
\begin{aligned}
& w_{j}=p_{j_{0}}+p_{j_{1}} x_{1}+\ldots+p_{j_{n}} x_{n} \\
& y=\sum_{j=1}^{m} \overline{\alpha_{j}} w_{j}
\end{aligned}
$$

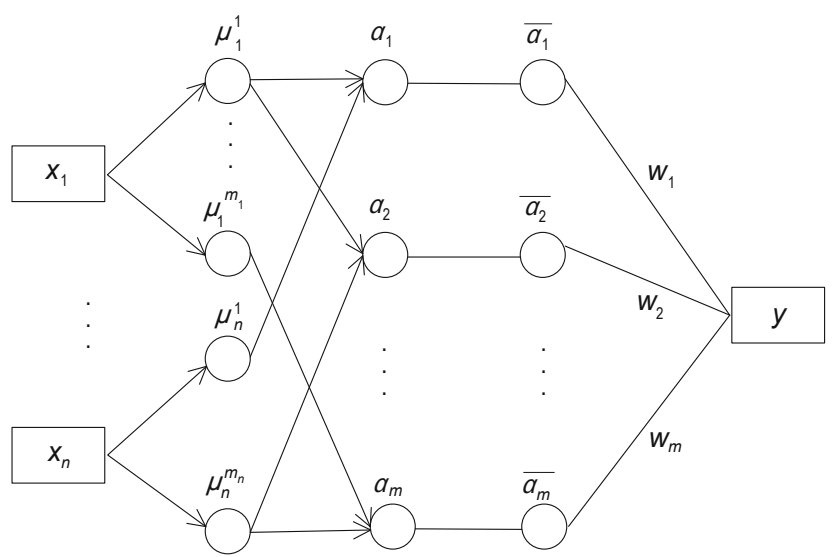

Fig. 5 Structure of NFIM

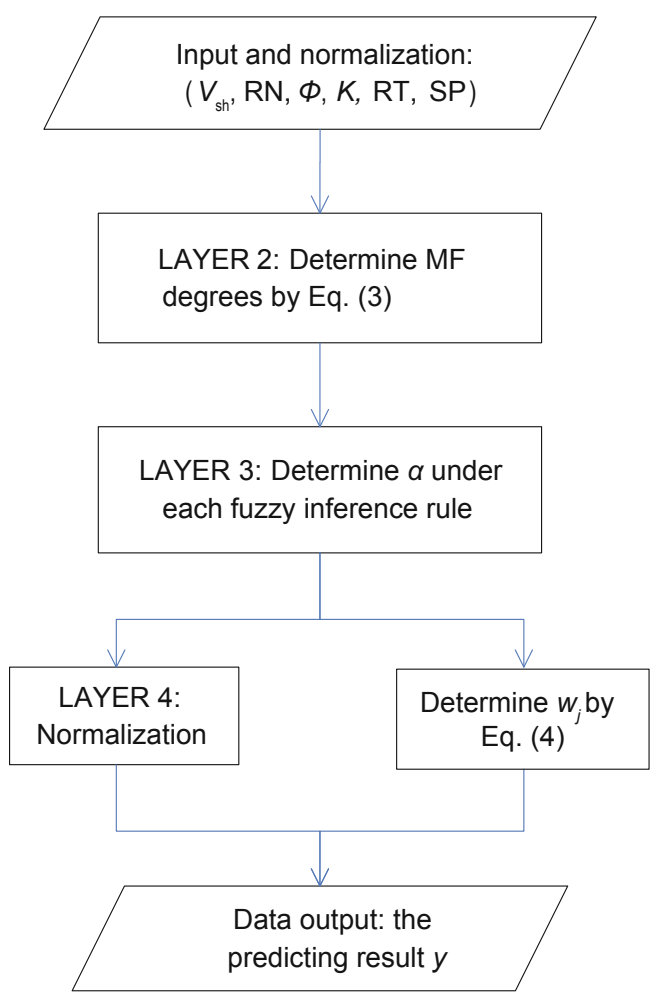

Fig. 6 Workflow diagram of the NFIM

The MF numbers of the inputs: $V_{\text {sh }}, \mathrm{RN}, \Phi, K$, RT and SP are 4, 4, 3, 3, 3 and 3 respectively. The output is the identification result with numbers 1 through 4 in accordance with the well testing results: oil layer, oil and water, water layer and dry layer. They are ordered by oil potential and then by total products in accordance with the parameter RN. Two points should be noted:

1) The MF numbers of $V_{\text {sh }}$ and $\mathrm{RN}$ are designed larger because lithology is the most fundamental and most sensitive parameter for identifying fluids.

2) Some clustering methods (Gao, 2004) or expert knowledge can be taken to reduce rules if there are too many to train rapidly.

Fig. 7 shows that the minimum MSE will be obtained after 341 iterations. It will be over-trained after that point. So the number of iterations was set 341 to get the best NFIM structure. Thus, a well-trained NFIM has been established successfully. Fig. 8 shows its prediction results compared with real field data. The output numbers will transform to the nearest integers to get ultimate classification results. The agreement rates are $100 \%$ among training, checking and real data.

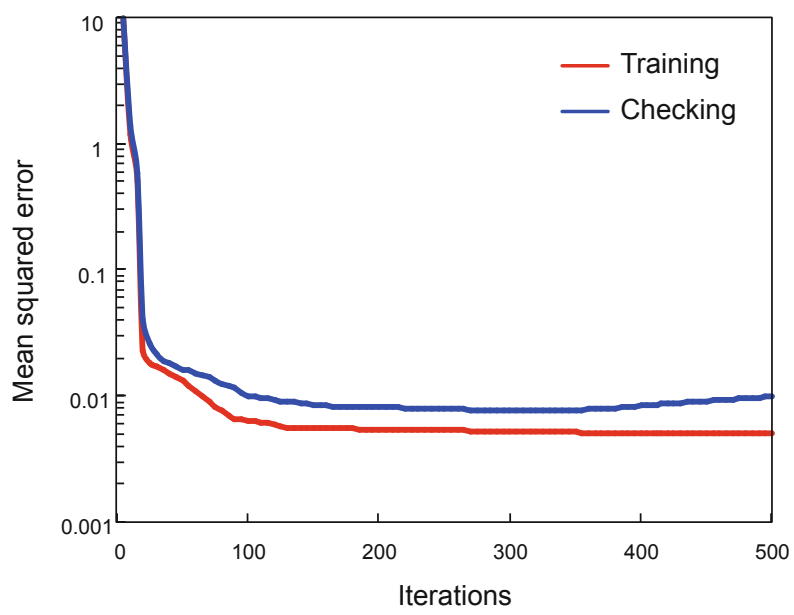

Fig. 7 Performance of the NFIM training and checking data against iterations

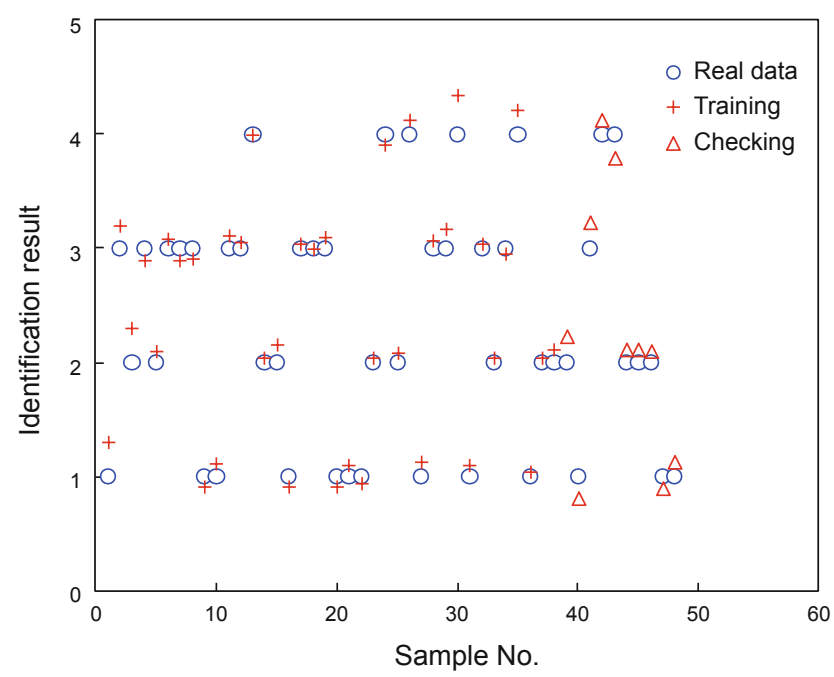

Fig. 8 Comparison between real data and IPIS predictions

\section{Applications}

The well-trained IPIS was programmed into a software set using Visual Basic script. Fig. 9 shows the comparison of IPIS interpretation conclusions with final well testing results for well A. Porosity and permeability from IPIS agreed well with the core data. The identification results are scatter points every $0.125 \mathrm{~m}$. The final layers were obtained by merging 
adjacent points which have the same results. So the layering process was automatic. The upper layer (2,285-2,297 m) is identified as an oil layer by the conventional method. However, IPIS results are water layer and dry layer. And the well testing result is a water layer with $26.2 \mathrm{~m}^{3} / \mathrm{d}$ production finally. The lower layer $(2,321-2,328 \mathrm{~m})$ is identified as a poor oil layer by the conventional method. However, IPIS result is an oil and water layer. The final testing result was an oil and water layer with an oil production of $8.34 \mathrm{t} / \mathrm{d}$, and water production of $9.89 \mathrm{~m}^{3} / \mathrm{d}$. Eighteen layers of $145.3 \mathrm{~m}$ total effective thickness from 10 new wells were examined by both conventional methods and IPIS. There was a complete agreement between IPIS results and final well testing results. It is obvious that the final models and software have obtained good results in the eastern Junggar Basin. However, it seems not always so effective in other areas. The models should be established carefully according to the goal formations based on IPIS ideas.

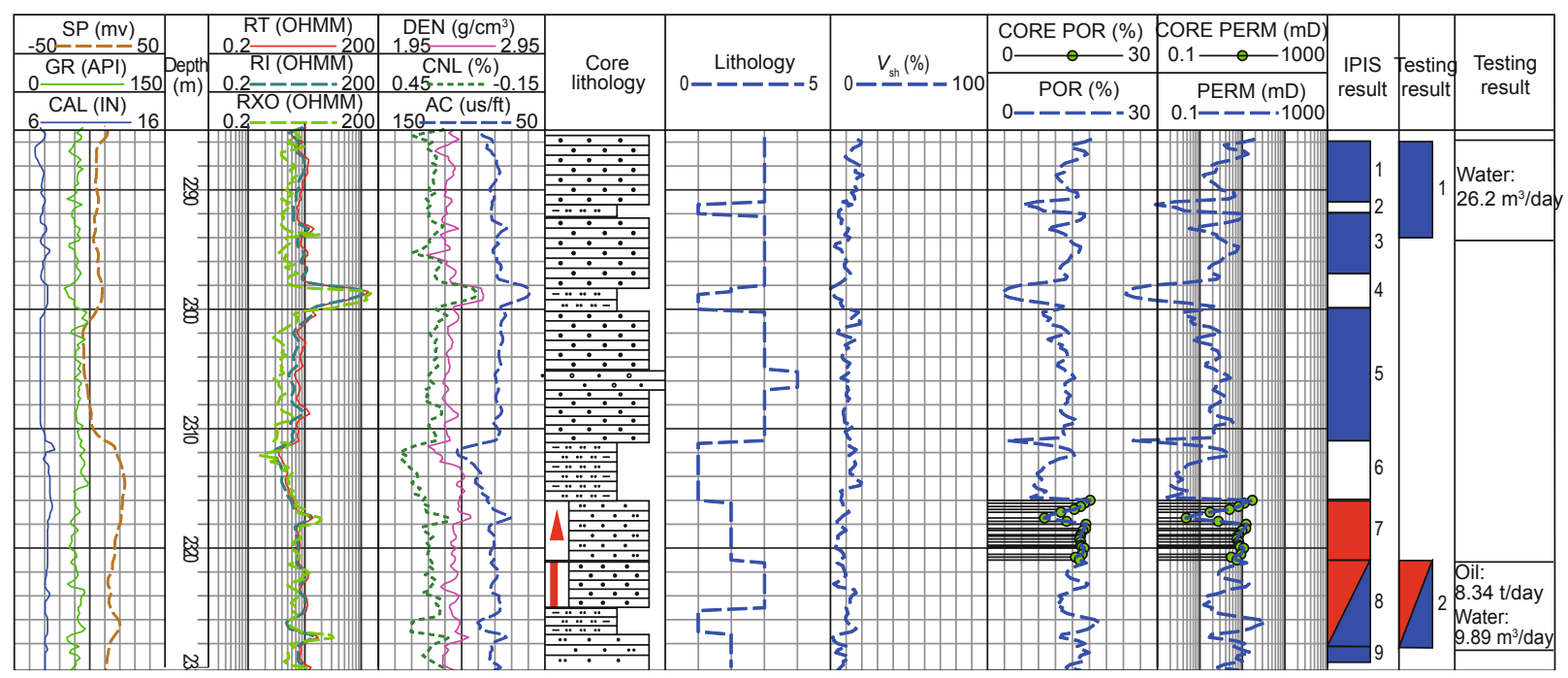

Fig. 9 Identification results for well A

\section{Conclusions}

1) Using conventional methods to identify potential pay zones in exploration wells is often time-consuming and inaccurate when the formations are complex and well log data are redundant.

2) An intelligent prediction and identification system (IPIS) based on an artificial neural network (ANN) and a fuzzy inference system (FIS) theory has been proposed to improve conventional methods. The IPIS has chosen six factors reflecting lithological, petrophysical properties and electrical responses. Firstly, shale content $\left(V_{\text {sh }}\right)$, porosity $(\Phi)$ and permeability $(K)$ are predicted by ANNs from well logs respectively. Then, rock type number (RN), $V_{\text {sh }}, \Phi, K$, RT, SP are input into a neuro-fuzzy inference machine (NFIM) to get the recognition results.

3 ) Some key points should be noted for IPIS. The six inputs are selected under standards based on fully understanding the formation situations. Enough numerical experiments have been done to avoid local convergence and to get the best structures and input sets of ANNs. The NFIM is more fault-tolerant than a normal BP net. The number of iterations will be set to 341 to prevent overfitting and get the best weights.

4) The agreement rate to recognize 10 layers between IPIS and well testing results is $100 \%$. Totally $145.3 \mathrm{~m}$ have been correctly recognized by IPIS. It has provided an effective methodology and a new direction in identifying sophisticated reservoirs.

\section{Acknowledgements}

This paper is financially supported by the National Science and Technology Major Demonstration Project 19 (2011ZX05062-008).

\section{References}

Amaefule J O, Altunbay M, Tiab D, et al. Enhanced reservoir description: using core and log data to identify hydraulic (flow) units and predict permeability in uncored intervals/wells. SPE26436. 1993

Bhatt A and Helle H B. Committee neural networks for porosity and permeability prediction from well logs. Geophysical Prospecting. 2002. 50(6): 645-660

Bloch S. Empirical prediction of porosity and permeability in sandstones. AAPG Bulletin. 1991. 75(7): 1145-1160

Burney S M A, Jilani T A and Ardil C. Levenberg-Marquardt algorithm for Karachi stock exchange share rates forecasting. Trans. Eng. Comput. Technol. 2004. 3: 1305-1313

Cheng X Z. Study of recognition technology and distribution law on low-resistivity oil reservoirs. Doctoral Dissertation. China University of Petroleum (East China). 2008 (in Chinese)

Cranganu $\mathrm{C}$ and Breaban $\mathrm{M}$. Using support vector regression to estimate sonic log distributions: A case study from the Anadarko Basin, Oklahoma. Journal of Petroleum Science and Engineering. 2013. 103(3): $1-13$

Elshafei M and Hamada G M. Neural network identification of hydrocarbon potential of shaly sand reservoirs. SPE110959. 2007

Fernandes M A. Using neural networks for determining hydrocarbons presence from well logs: A case study for Alagoas Basin. SPE153446. 2012 
Gao R F, Wang X Y and Cheng G J. Identification of oil and gas reservoirs based on emergent spontaneous-organizing feature maps. Journal of Xi' an Shiyou University (Natural Science Edition). 2009. 24(6): 74-77 (in Chinese)

Gao X B. Fuzzy cluster analysis and its applications. Xi'an: Xidian University Publishing House. 2004 (in Chinese)

Hagan M T, Demuth H B and Beale M H. Neural Network Design. USA: PWS Publishing Company. 1996

Li G Y. Intelligent Predictive Control and MATLAB (2nd edition). Beijing: Publishing House of Electronics Industry. 2010 (in Chinese)

Li S Y. Fuzzy Control, Neurocontrol and Intelligent Cybernetics. Harbin: Harbin Institute of Technology Press. 1998 (in Chinese)

Li X Y, Li H Q, Zhou J Y, et al. Identification of the Quaternary low gassaturation reservoirs in the Sanhu area of the Qaidam Basin, China. Petroleum Science. 2011. 8(1): 49-54

Li Z B. Drilling Geophysical Exploration. Beijing: Geological Publishing House. 2006 (in Chinese)

Jafari A and Moghadam R H. Integration of ANFIS, NN and GA to determine core porosity and permeability from conventional well log data. Journal of Geophysics and Engineering. 2012. 9(5): 473

Jafari S A and Mashohor S. Robust committee machine for water saturation prediction. Journal of Petroleum Science and Engineering. 2013. 104(4): 1-10

Jafari S A, Mashohor S and Varnamkhasti M J. Committee neural networks with fuzzy genetic algorithm. Journal of Petroleum Science and Engineering. 2011. 76(3): 217-223

Kadkhodaie I A, Rahimpour B H and Rezaee M. A committee machine with intelligent systems for estimation of total organic carbon content from petrophysical data: An example from Kangan and Dalan reservoirs in South Pars Gas Field, Iran. Computers \& Geosciences. 2009a. 35(3): 459-474

Kadkhodaie I A, Rezaee M R and Rahimpour B H. A committee neural network for prediction of normalized oil content from well log data: An example from South Pars Gas Field, Persian Gulf. Journal of Petroleum Science and Engineering. 2009b. 65(1): 23-32

Karimpouli S, Fathianpour N and Roohi J. A new approach to improve neural networks' algorithm in permeability prediction of petroleum reservoirs using supervised committee machine neural network (SCMNN). Journal of Petroleum Science and Engineering. 2010. 73(3): 227-232

Khoshnoodkia M, Mohseni H, Rahmani O, et al. TOC determination of Gadvan Formation in South Pars Gas field, using artificial intelligent systems and geochemical data. Journal of Petroleum Science and Engineering. 2011. 78(1): 119-130

Tan F, Li H, Xu C, et al. Quantitative evaluation methods for waterflooded layers of conglomerate reservoir based on well logging data. Petroleum Science. 2010. 7(4): 485-493

Wang $\mathrm{K}$ and Zhang L. Predicting formation lithology from log data by using a neural network. Petroleum Science. 2008. 5(3): 242-246

Wang X J, Hu G M and Cao J X. Application of multiple attributes fusion technology in the Su-14 Well Block. Applied Geophysics. 2010. 7(3): 257-264

Wu R, Chen W, Chen T, et al. A time-driven transmission method for well logging networks. Petroleum Science. 2009. 6(3): 239-245

Ye S, Lü Z and Li R. Petrophysical and capillary pressure properties of the upper Triassic Xujiahe Formation tight gas sandstones in western Sichuan, China. Petroleum Science. 2011. 8(1): 34-42

Yu X C, Dai S, Hu D, et al. The hierarchical hybrid fuzzy-neural network based on lasso function and its application to classification of remote sensing images. Chinese Journal of Geophysics. 2011. 54(4): 590-598 (in Chinese)

Zhang J C, Liu L and Song K P. Neural approach for calculating permeability of porous medium. Chinese Physics Letters. 2006. 23(4): 1009-1011

Zhang J H, Liu Z, Zhu B H, et al. Fluvial reservoir characterization and identification: A case study from Laohekou Oilfield. Applied Geophysics. 2011. 8(3): 181-188

Zhou C D, Wu X L and Cheng J A. Determining reservoir properties in reservoir studies using a fuzzy neural network. SPE 26430. 1993

Zhu K G, Lin J, Han Y H, et al. Research on conductivity depth imaging of time domain helicopter-borne electromagnetic data based on neural network. Chinese Journal of Geophysics. 2010. 53: 743-750

(Edited by Hao Jie) 